unaccustomed occupation-the trade itself must be adjusted to the man and not the man to the trade. Let his technical ability - of ten acquired during a long apprenticeship-have full play: it can never be replaced by a trade learnt in later life, and the ease with which certain processes in his own trade may be accomplished makes it all the more suitable for the disabled man, provided the adverse conditions attaching to the trade are removed. It is useless to go into minute detail for each trade. Each has to be carefully studied, always bearing in mind the main principles which underlie the whole problem.

\title{
RACIAL DIFFERENCES IN SUSCEPTIBILITY TO TUBERCULOSIS.
}

\author{
By Colonel S. L. Cumimins, \\ C.B., C.M.G., LL.D., M.D., \\ Professor of Pathology in the Royal Army Medical Corps College, \\ Millbank, London.
}

WHILST engaged in an investigation into tuberculosis in the Egyptian Army in 1907, my attention was attracted by what was to me, at that time, an unexpected and highly interesting phenomenon, the association between high individual susceptibility to the disease and a tribal origin excluding all likelihood of previous contact with the tubercle bacillus.

In a paper published in this Journal in the following year ${ }^{1} I$ showed that the incidence and mortality from this disease was very much greater amongst the Sudanese troops recruited from the remote regions of the Upper Nile than amongst the Egyptian soldiers conscripted from the fellaheen of the Delta. Evidence was produced to show that the disease was practically unknown in man or cattle in the Dinka and Shilluk countries, whence our best Sudanese soldiers were drawn, while it was relatively common in Egypt. The bearing of this observation upon the epidemiology of tuberculosis was at once evident, and on my return to England I continued to keep in touch with the literature bearing on this aspect of the disease. A few experiments in the use of the Von Pirquet test carried out at Netley Hospital in $1909^{2}$ opened my eyes to the fact that individuals clinically free from all traces of the disease gave as high a proportion of positive reactions as a group of patients known to be suffering from tuberculosis, showing that these

1 Cummins, S. L.: "Tuberculosis in the Egyptian Army." British Journal of Tuberculosis, Vol II., No. I, January, Igo8.

2 Cummins, S. L.: "On Surface Vaccination in Suspected Cases of Tubercle." Iournal of the Royal Army Medical Corps, June, rgog. 
apparently normal persons had been in contact with the tubercle bacillus, and I was thus led to study the records of the application of this test as a guide to the distribution of infection amongst "primitive" communities.

It was in this way that the significance of the work of Metchnikoff, Burnet, and Tarassewitch ${ }^{1}$ amongst the Kalmucks came to my notice, bringing with it a full realization of the importance of "acquired resistance" as a factor in the limitation of the diffusion and the severity. of the disease, and in a paper read before the Society of Tropical Medicine and Hygiene ${ }^{2}$ in Igr 2 I attempted to call attention to an aspect of tuberculosis that deserves close attention in an Empire such as ours, with wide Colonial responsibilities and interests. In this paper I ventured to draw the following conclusions: "(I) That 'primitive' tribes are highly susceptible to tuberculosis because, in the absence of the tubercle bacillus, they have never been obliged to protect themselves against that organism; (2) that 'civilized' peoples are highly protected against tuberculosis because they have, in contact with the tubercle bacillus, elaborated protective substances against that organism."

The contention that the "virgin soil " theory is the real explanation of the admitted susceptibility of African and other primitive tribesmen when brought into contact with Europeans has sometimes been met by the suggestion that alcoholic excess, poverty, bad housing, poor food, and defective sanitation are equally likely to induce a high incidence in such individuals. The late war, however, afforded a unique opportunity for contrasting the susceptibility to tuberculosis shown by varying racial contingents, consisting of men of comparable age, living outside their original environment under more or less similar conditions of housing, clothing, and nutrition. The opportunity was not exploited as it might bave been. War conditions and the never-relaxing strain upon medical services combined to throw great difficulties in the path of research. In the French Army an expert with every possible qualification for the work was specially detailed to investigate a question that was recognized as of vital importance, and to this circumstance we owe the invaluable observations of Dr. Borrel, which have recently appeared in the annals of the Pasteur Institute. ${ }^{3}$

In the British zone, the various native labour units working upon the lines of communication presented a similar problem, and the statistical records kept up in the office of Colonel (now Brig.-General)

1 Metchnikoff, E., Burnet, E., and Tarassewitch : "Recherches sur l'Epidemio. logie de la Tuberculose dans les Steppes des Kalmouks," Ann. de l'Inst. Pasteur, Vol. XXV., No. II, November, IgII, p. 715 .

2 Cummins, S. L.: "Primitive Tribes and Tuberculosis," Transact. Society Tropical Medicine and Hygienle, Vol. V., No. 7, June, I9I2, p. 245.

3 Borrel, A.: "Pneumonie et Tuberculose chez les Troupes Noires," Ann. dé lInst. Pusteur, Vol. XXXII., No. 3, March, 1920, p. I05. 


\section{I62 THE BRITISH JOURNAL OF TUBERCULOSIS}

W. W. O. Beveridge, C.B., the Assistant Director of Medical Services for Sanitation, show that the response of these susceptible individuals to contact with the degree of infection met with in camps and billets was comparable, in regard to morbidity and mortality, to that observed by Borrel among Senegalese troops. It will be some time before the information stored up in our Admission and Discharge Books, Card Index Records, and Case Sheets can be analyzed and made available. Some idea of the vast differences in susceptibility to tuberculosis shown. by various racial communities represented in the fighting forces and labour contingents of the British Expeditionary Force in France will be gained by a glance at the following table.

\section{Table showing the Incidence and Mortality of Tuberculosis} in B.E.F. in France in igi8.

\begin{tabular}{|c|c|c|}
\hline & $\begin{array}{c}\text { Annual Case } \\
\text { Incidence } \\
\text { per ro, ooo of } \\
\text { Average Annual } \\
\text { Strength. }\end{array}$ & $\begin{array}{l}\text { Annual Deaths } \\
\text { per Io,ooo of } \\
\text { Average Annual } \\
\text { Strength. }\end{array}$ \\
\hline South African Native Labour Corps & $x 86$ & I67 \\
\hline Cape Coloured Labour Corps... & 444 & 88 \\
\hline Indian Native Labour Corps ... & I 42 & 53 \\
\hline Chinese Native Labour Corps & 36 & I2 \\
\hline British Troops in France and Belgium & Io & 0.5 \\
\hline
\end{tabular}

Absolute accuracy cannot be claimed for these figures, but there can be no doubt that they are sufficiently correct to justify very definite conclusions.

It will at once be evident that the incidence and mortality varies inversely with the degree of possibility of previous contact with the tubercle bacillus. The Africans, both the Kaffirs of the South African Native Labour Corps and the Cape Boys of the Cape Coloured Labour Corps, show an incidence and a mortality that can only be described as appalling. The Indian Native Labour Corps comes next, then the Chinese. The incidence and mortality amongst British troops, drawn from the almost universally "infected" communities of a highly organized and largely urban population, is relatively inconsiderable. Here there can be no question of alcoholic excesses, bad housing, insanitary surroundings, or unsuitable food. Colonel Beveridge, with a full appreciation of the importance of the danger of tuberculosis, obtained for the African and other native labour units the same air space as that allowed for British troops. Their rations were on a most liberal and suitable scale. Unlike the British soldiers, whose lives 
were spent for the most part in the crowded "dugouts" and "shelters" of the battle line, these native contingents enjoyed the comparative comforts and amenities of the lines of communication and bases. The fact that every man was medically examined before leaving his own country excludes the possibility of the infection having preceded arrival in France in any but exceptional instances; and the rapid course of the disease and the much higher case incidence and death-rate in the second year of service with the British Expeditionary Force adds a further proof that the infection was acquired in France. Putting aside the obvious bearing of these facts upon the responsibility that devolves upon those who exploit "native" labour for industrial or military purposes, it is well to examine briefly their value as a clue to the solution of some of the outstanding problems of tuberculosis in general.

(I) The suggestion that there is an "hereditary tendency" more marked amongst the children of tuberculous parents than in the rest or the community must be seriously called in question in view of the extreme susceptibility shown by persons coming from a parent stock in which no tuberculous taint can have existed. The relatively high resistance amongst British troops, born in communities where tuberculosis is rife, adds to the necessity for reconsidering the conclusions drawn by Pearson from his statisfical studies. ${ }^{1}$

(2) The essential factor in susceptibility would appear to be largely unconnected with race, but to depend rather upon an absence of acquired resistance to infection. This acquired resistance can only be attained by contact with the tubercle bacillus. It is probable that the diminution in the tuberculous death-rate so marked throughout Great Britain in the last fifty years has depended less upon the efforts of those engaged in "stamping out" tuberculosis than upon the natural processes of auto-immunization that have gone on coincidently with the developments of industrial life.

(3) While there should be no slackening of the effort to control the spread of tuberculosis infection, it should be clearly recognized that this infection is much more dangerous at certain periods of life and to certain individuals than to the community in general. Infants and young children are "virgin soil." Young adults from the Shetlands or from the Welsh mountains, or from the country districts of Ireland, are likely to run much greater risks in Glasgow, Cardiff, Dublin, and other large centres than do the permanent inhabitants of these towns.

(4) If the efforts of all those engaged in attempting to prevent the spread of tubercle bacilli, human and bovine, were so far successful as to ensure that every young man and woman reached the wage-earning period without any contact with the germ, it is possible that the whole

1 Pearson, K. : "A First Study of the Statistics of Pulmonary Tuberculosis." London: Drapers' Company Research Memoirs, I907. 


\title{
I64 THE BRITISH JOURNAL OF TUBERCULOSIS
}

population would end by being as susceptible to infection as are the African tribesmen in their native isolation. Contact with less progressive nations might then have disastrous results. This equivocal success is never likely to be attained, and we are quite safe in doing all we can to guard against infection. Our best efforts can hardly do more than ensure that the omnipresent tubercle bacilli shall be ingested in minimal "immunizing" doses, rather than in such quantities as to prove too much for the gradually developing resistance. The future of tuberculosis prevention lies in the deliberate exploitation of immunization by means of vaccinating doses of dead or attenuated bacilli. How this end is to be obtained is the prime question for research workers upon tuberculosis.

\section{TUBERCULOSIS OF THE EAR.}

\author{
By DOUGLAS GUTHRIE, \\ M.D., F.R.C.S.,
}

Aural Surgeon to the Royal Hospital for Sick Children, Edinburgh.

THE delicate structures of the middie ear are most prone to be attacked by tuberculosis at the two extremes of a lifetime. We may encounter the disease during the period of infancy or during the last stages of pulmonary tuberculosis. In the latter case, the ear trouble is of the nature of a terminal infection, and is overshadowed by the graver primary lesion. The infantile type, on the other hand, is of much greater importance, as it is one of the disasters of infant life whose prevention and cure may be furthered by the work of the otologist. We may summarize the chief features under the following headings:

Fvequency. -The extraordinary frequency of acute otitis media in infancy has been the subject of repeated comment. Post-mortem evidence shows that middle-ear infection is present in no less than 82 per cent. of all infants, whatever the cause of death. It may readily be understood that a structure so vulnerable to acute infection will frequently be the seat of tuberculous invasion.

Age Incidence.-The great majority of cases of acute otitis in infants undergo a natural cure-indeed, chronic otitis is a rare disease of infant life, apart from tuberculosis. It may even be said that the mere chronicity (duration over two months) of aural suppuration in a child under one year old should lead one to suspect its tuberculous nature. The writer has elsewhere reported a series of thirteen cases of aural tuberculosis, in all of which the disease had commenced during the 